\title{
Analysis of Urban Car Owners Commute Mode Choice Based on Evolutionary Game Model
}

\author{
Huawei Gong ${ }^{1,2}$ and Wenzhou Jin ${ }^{1}$ \\ ${ }^{1}$ School of Civil Engineering and Transportation, South China University of Technology, No. 381 Wushan Road, \\ Tianhe District, Guangzhou 510641, China \\ ${ }^{2}$ School of Civil Engineering, Guangzhou University, Panyu University City Outer Ring Road No. 230, Guangzhou 510006, China
}

Correspondence should be addressed to Huawei Gong; gonghw@gzhu.edu.cn

Received 16 November 2014; Revised 9 February 2015; Accepted 10 February 2015

Academic Editor: Hung-Yuan Chung

Copyright (C) 2015 H. Gong and W. Jin. This is an open access article distributed under the Creative Commons Attribution License, which permits unrestricted use, distribution, and reproduction in any medium, provided the original work is properly cited.

\begin{abstract}
With the aggravation of the traffic congestion in the city, car owners will have to give up commuting with private cars and take the public transportation instead. The paper uses the replication dynamic mechanism to simulate the learning and adjustment mechanism of the automobile owners commuting mode selection. The evolutionary stable strategy is used to describe the longterm evolution of competition game trend. Finally we simulate equilibrium and stability of an evolution of the game under a payoff imbalance situation. The research shows that a certain proportion of car owners will choose public transit under the pressure of public transport development and heavy traffic, and the proportion will be closely related to the initial conditions and urban transportation development policy.
\end{abstract}

\section{Characteristics of Urban Transportation}

The core issue of urban transportation development is how to treat private car and public transportation development in almost big cities worldwide. Different urban transportation development policies are roughly divided into three patterns: the first category is the automobile dependence mode, the representative of the country is USA, the family car ownership is very high, and private car used in commute ratio also is high. The second type is the private car synchronization coordinated with rail transit development, such as London, Paris, and Tokyo, and so forth, the car ownership is not lower than the north American cities, but the car utilization rate is low, and people commute mainly using the subway. The third type of city transportation mainly relies on public transport, inhibiting vehicle holdings growth and car use ratio, such as Singapore, Hong Kong, and other cities. It has formed a consensus on urban transportation development policy that a city must be rational to increase the number of cars, and none of the big cities can satisfy the unlimited increase of the cars through continuous road construction only. The big city transportation depends on the priority development of public transport. The big cities traffic problems are very complex; the cities must formulate their own transportation strategy according to their respective conditions and study.

China is in the period of social and economy high speed development. The speeding-up development of urbanization and motorization of big cities caused a series of problems as traffic jams, pollutions, energy consumption, and so on. With the improvement of people's living standard in recent years, more and more families have private cars; the traffic congestion becomes more serious in many cities. The road mileage growth cannot meet the growth of traffic demand. The government should take some policies to limit the use of private cars through economic means to reduce the private car use, alleviate the pressure of the traffic jams, and implement bus priority strategy. Public transportation is a traffic mode of less per capita road resources and large passenger capacity; with the characteristics of energy conservation and environmental protection, it is an intensive mode of 
transportation. As the important infrastructure of the city, for most people the equal rights, public transportation embodies the social fairness and justice. Under the condition of traffic individual freedom to choose the means of commute, rational individuals prefer to consume public road resource from the self-interest. Because of two defining characteristics, nonexcludability and nonrivalry of the public facilities, the individual profit in the use of public resources completely from self-interest is far lower than the overall optimal profit, which results in the difficulties of sustainable development of the urban traffic system; it is the typical "public facilities tragedy" in game theory, which was known as the "Harding Tragedy" Therefore the government must control the increase in the number of cars and the usage of private cars; at the same time the government should encourage the use of public transportation way to commute.

A larger amount of research results in the urban transportation development patterns by using the game theory. Only two types of travel modes, namely, autobus and private car, are considered in [1], and a two-level game model has been formulated with the purpose to make reasonable and sufficient use of the limited traffic resources. In [2], the evolutionary process of trip model choice behavior of traffic traveler is analyzed by using evolutionary game, and an evolutionary model is proposed. Then the main parameters' affection to the choice behavior is also analyzed. The results show that the government's impelling to the public transport and penalty to the private vehicle play an important role in evolution of traffic individual's behavior, which may provide corresponding reference to the government's decision-making body. Reference [3] presents an evolutionary game model of travel mode choice for single population and proposes the evolutionary stable strategy about travel mode choice, which provides some academic support and evaluation for traffic management measures. In these articles, the researchers have been trying to analyse the result of urban transportation choice by using the game theory, and some of the city traffic travel choice behaviors are analyzed, but these studies have neglected the car owners' choice difference, especially under the conditions that the city traffic development will be a great change in the future.

For research of commute traffic mode selection, the initial conditions are the most important factor of the method of random utility theory. Reference [4] formulates a nested logit NL model which is based on the random utility maximum theory, and they believe the commute mode choice mainly is decided by the effects of sociodemographics, land use characteristics, and trip attributes, so they investigate the income, age, employment accessibility, travel time, and travel cost of commuters. Reference [5] examines system optimum solutions for neighborhood-sized urban networks with cars and transit that serve a demand which is distributed in time and space, and which may include a population of captive transit riders. The research shows that the network capacity for cars is reduced if transit operations receive dedicated street space. The analysis shows how the transit agency should operate and how to set fares and tolls to minimize the system's generalized cost.
In this paper, we study the choice of the mode of China's urban transportation development based on the following assumptions:

(1) Urban car ownership will continue to increase; the growth will keep the high level because of China's economic development and urban residents' income increase in a relatively long period of time.

(2) Though the urban car ownership maintains growth, the public transit will get further development for the city traffic capacity constraints. Under some restrictions on private car use and policies on improving the service level of public transport, part of commuters may give up using car commuter and switch to public transportation mode. So in the future urban transportation development mode, there is not a necessarily direct correspondence between car usage and the growth of car ownership. We hope to analyse the choice of commute mode of urban car ownership family in the future under these assumptions. It would provide the beneficial reference for the public transportation development strategy and help us to plan development policy of urban transportation.

\section{The Evolutionary Game Model of Car Owners' Travel Mode Choice}

In the classical game theory, Nash equilibrium is the most important concept, it requires that the game players be perfectly rational and with infinite regression reasoning ability. In the process of game the players always make strategy works best for themselves. But in reality, we cannot assume that game participants always make perfectly rational decisions and must consider the game player's decision may be limited by the uncertainty factors of interference, which may lead to an unachievable Nash equilibrium. If game participants follow the behavior logic of temptation-learnadapt-growth in decision, that is the concept of Evolutionary Stable Strategy (ESS) [6]. In the process of the game, players have limited information of individuals. According to their vested interests, players adjust their strategy to improve their own payoffs on the marginal constantly. The limited rational users study and adjust to balance strategy in the sense of a group, the equilibrium strategies are called Evolutionary Stable Strategy, and the game process is described as evolution of the game.

In the dynamic game model of car owners travel mode choice, we assume that there are two types of participants in the game; pure strategy is used by all participation. The $S$ is defined as the set of all pure strategies, function $\omega_{t}(s)$ is represented by pure strategy set $s \in S$ when all the participants can be adopted in phase $t$, the state variable $\theta_{t}(s)$ is denoted by proportion vector in phase $t$ with pure strategy $s$, and the function $u(s, r)$ is denoted by the expected utility of participants group who adopt pure strategy $s$ when the other participants group is using pure strategy $r$. Variable $\bar{u}_{t}$ is denoted by average expected utility of all participants. 
TABLE 1: The payoffs matrix of car owners by choosing different mode to commute.

\begin{tabular}{lcc}
\hline Group A & \multicolumn{2}{c}{ Group B } \\
& $\begin{array}{c}\text { Commute by } \\
\text { public transit }\end{array}$ & $\begin{array}{c}\text { Commute } \\
\text { by car }\end{array}$ \\
\hline Commute by public transit & $U_{B}, U_{B}$ & $V_{B}, V_{P}$ \\
Commute by car & $V_{P}, V_{B}$ & $U_{P}, U_{P}$ \\
\hline
\end{tabular}

According to the certificate in [3], we can get the following conclusion:

$$
\frac{d \theta_{t}(s)}{d t}=\theta_{t}(s) \cdot\left[u_{t}(s)-\bar{u}_{t}\right] .
$$

This is an imitator replicated dynamic equation, and it satisfies the following theorem: (Fudenberg, 1998) a stable state of imitator dynamic is a Nash equilibrium; more generally, any steady state originated from the limitative internal path is a Nash equilibrium. On the other hand, if there exists a $\delta>0$ for a non-Nash equilibrium, all internal path will eventually be cleared from the neighborhood of the steady state $\delta$.

\section{Establishing a Game Model}

As stated earlier, in the future urban commute mode selection, part of the car owners will give up driving and commute by the public transit with the development of urban public transportation. All car owners were divided into two categories, group A and group B, in our game model. Each group selects commuter bus or driving according to certain proportion, the analysis about payoffs being as follows: (1) when both group members choose public transit, payoffs of both sides are $U_{B} ;(2)$ when one group chooses private cars and the other group chooses public transit, the game payoffs are $\left(V_{B}, V_{P}\right)$ and $\left(V_{P}, V_{B}\right)$, respectively; (3) when both group members choose private cars, the payoffs are both $U_{P}$. The payoffs matrix is shown in Table 1.

Assumption of the proportion of car owners who choose to take public transit is $x$, and the proportion of car owners who use cars is $1-x$. The game is randomly matched groups; then we apply the above analysis result; the participants payoffs are denoted by $\pi$; the benefit of players who take public transit is

$$
\pi^{B}=x \cdot U_{B}+(1-x) \cdot V_{B} .
$$

The benefit of players who use car is

$$
\pi^{P}=x \cdot U_{P}+(1-x) \cdot V_{P} .
$$

For all players average benefit is

$$
\pi=x \cdot \pi^{B}+(1-x) \cdot \pi^{P} .
$$

Obviously in the general case, there are differences benefits between the two group participants. According to (1), the dynamic changes of the proportion of the participants who take public transit can be represented as

$$
\frac{d x}{d t}=x \cdot\left(\pi^{B}-\pi\right) \text {. }
$$

Equation (5) is replicated dynamic equation which is described for the proportion of car owners who choose public transit mode. Substituting (2) and (4) into (5), we get

$$
\frac{d x}{d t}=x \cdot(1-x)\left[x\left(U_{B}-V_{P}\right)+(1-x)\left(V_{B}-U_{P}\right)\right] .
$$

For the convenience, we assume that the profit of all strategies under the combination is a constant, so derivative $d x / d t$ is only the function of $x$; then (6) can be written as

$$
F(x)=\frac{d x}{d t} .
$$

To discuss the evolutionary stable strategy of the game model, we can find out the replication dynamic stable state firstly; after that we can discuss the influence of disturbance to the steady-state.

Let $F(x)=0$; we can get three stable states from (7):

$$
\begin{gathered}
x_{1}=0, \\
x_{2}=1, \\
x_{3}=\frac{V_{B}-V_{P}}{U_{B}-V_{B}-V_{P}+U_{P}} .
\end{gathered}
$$

As the different values of payoffs, $x_{3}$ may be equal to $x_{1}$, $x_{2}$ or does not exist $\left(x_{3} \notin[0,1]\right)$; then the game degenerates into only two stable states.

As an evolutionary stable strategy $x^{*}$ must be a stable point, when it is given a small perturbation, it will still come back by replicated dynamic. According to the differential equation of stability theorem, that derivative $F(x)$ must be less than zero in place of $x^{*}$. It means when interference $x$ is below $x^{*}, F(x)$ must be greater than 0 ; when the interference $x$ is above $x^{*}, F(x)$ must be less than 0 . Reflected on the phase diagram, $F(x)$ with horizontal axis intersection point tangent slope is negative in the place $x^{*} ; x^{*}$ is the corresponding game replication dynamic evolutionary stable strategy at this time.

\section{The Example of the Evolutionary Game Model of the Commute Mode Choice under the Benefit Imbalance Situation}

We have described a general benefit structure under two symmetrical methods for analyzing the stability of the equilibrium of cooperative game. In fact in car owners group, people have different sensitivity for travel time and the cost of commute. We define group A as a low income group; they will tend to choose public transit commute under the condition of lower public transit fee or higher private car costs; at the same time we define group B with higher income level; even if the public transit fee is lower or private car travel cost is higher, they still incline to use private cars. In this setting, the game model of group A and group B is no longer the previous benefits symmetric balanced game and changes into differentiation level gaming revenue. For the sake of convenient calculation, we assume that the payoffs are the dimensionless numbers; an evolutionary game model 
TABLE 2: The disequilibrium payoffs matrix of game model in choosing different commute mode.

\begin{tabular}{lcc}
\hline \multirow{2}{*}{ Group A } & \multicolumn{2}{c}{ Group B } \\
& $\begin{array}{c}\text { Commute by } \\
\text { public transit }\end{array}$ & $\begin{array}{c}\text { Commute } \\
\text { by car }\end{array}$ \\
\hline Commute by public transit & 8,2 & 0,6 \\
Commute by car & 12,0 & $-3,-9^{*}$ \\
\hline
\end{tabular}

* Means all car owners commute by private cars, it makes the traffic conditions get serious worse, so the payoffs of game players are negative.

is established for numerical simulation analysis. The payoffs matrix is shown in Table 2 .

Assume that the game payoffs structure is as follows: in group $\mathrm{A}$, the proportion of using public transit is $x$; then the proportion of using private cars is $1-x$; in group $\mathrm{B}$ the proportion of using public transit is $y$; then the proportion of using private cars is $1-y$. The benefits of participants of group $\mathrm{A}$ are as follows:

$$
\begin{gathered}
\pi_{1}^{B}=8 y, \\
\pi_{1}^{P}=15 y-3 .
\end{gathered}
$$

According to (8), we have

$$
\pi_{1}=x \cdot \pi_{1}^{B}+(1-x) \cdot \pi_{1}^{P}=-7 x y+3 x+15 y-3 .
$$
follows:

Similarly, benefits of participants in group B are as

$$
\begin{gathered}
\pi_{2}^{B}=2 x, \\
\pi_{2}^{P}=15 x-9, \\
\pi_{2}=y \cdot \pi_{2}^{B}+(1-y) \cdot \pi_{2}^{P}=-13 x y+15 x+9 y-9 .
\end{gathered}
$$
are

Applying (13), two groups of replicated dynamic equation

$$
\begin{aligned}
& \frac{d x}{d t}=x \cdot(1-x) \cdot(7 y-3), \\
& \frac{d y}{d t}=y \cdot(1-y) \cdot(13 x-9) .
\end{aligned}
$$

Analyzing the replication dynamic equation of participants of group A, as shown in (12), when $y=3 / 7$, there is $d x / d t \equiv 0$; that is to say, to any value of $x$, the systems are stable state. When $y>3 / 7$, there are two steady state $x_{1}=0$ and $x_{2}=1$, and $x_{2}=1$ is the evolutionary stable strategy. When $y<3 / 7$, the steady state still is $x_{1}=0$ and $x_{2}=1$, and $x_{1}=0$ is evolutionary stable strategy.

Similarly, analyzing the replication dynamic equation of participants of group B, as shown in (13), when $x=9 / 13$, there is $d y / d t \equiv 0$; that is to say, to any value of $y$, the systems are stable state. When $x>9 / 13$, there are two steady state $y_{1}=0$ and $y_{2}=1$, and $y_{2}=1$ is the evolutionary stable strategy. When $x<9 / 13$, the steady state still is $y_{1}=0$ and $y_{2}=1$, and $y_{1}=0$ is evolutionary stable strategy.

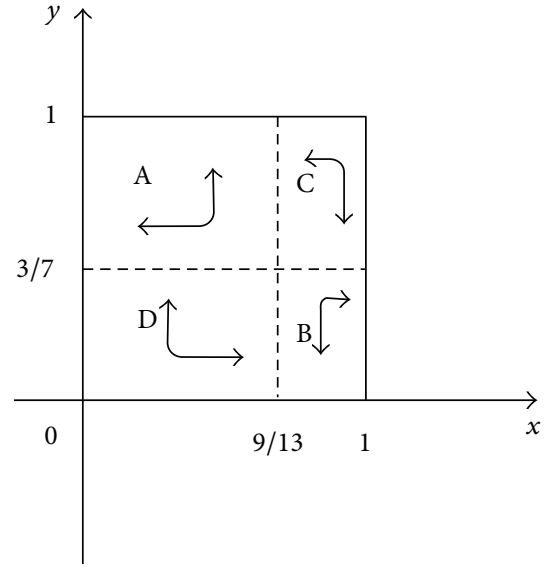

FIgURE 1: Dynamic evolution game trend of car owners commutes mode choice.

The two types of participants in the cooperative competition replication dynamic relationship graph are shown in Figure 1.

From Figure 1 we can come to a conclusion: points $(1,0)$ and $(0,1)$ are the evolutionary stable strategy in game as shown in Table 2; the system finally converges to the strategy decided by the initial state of the system. When the initial state falls in area A, the system will converge to $(0,1)$, the group A will choose the strategy of cars commute, and group $\mathrm{B}$ will choose the public transit as commute mode. When initial state falls in area $B$, the system will converge to $(1,0)$, group A will adopt strategy of the public transit commute, and group B will adopt the strategy of cars commute. When the initial state falls in area $\mathrm{C}$ or $\mathrm{D}$, the direction of system evolution is uncertain; it may enter into area $\mathrm{A}$ and converge to point $(0,1)$; it is also likely to enter area $B$ and converge to point $(1,0)$; it reflects the diversity of competition strategy of reality. We can draw a conclusion from the above analysis that the system has the characteristics of the evolution of complex system; $x=9 / 13$ and $y=3 / 7$ are change threshold of system evolution characteristics. When the system's initial state is in the vicinity of the two values, the initial state of the small changes will affect the final result of system evolution; this is the system sensitivity to initial conditions, when the system initial state in A, B, A final state of system evolution is determined; it shows that the results of the system evolution depend on the initial conditions.

\section{Conclusion}

From the above analysis of evolutionary game model, we know the commute mode choice is mainly affected by the factors of travel time, travel cost, and comfort level, and so forth. When the urban road traffic system cannot carry more and more private cars, commute by private cars is no longer the only optimal way. The commute mode of developed countries' change has shown this problem. The commute mode choice of urban car owners is related to the public transport system development and private travel restriction 
policy; these factors ultimately impact on car owners' choice proportion.

We compare the conclusion with the other research results, [7] based on the analysis of data drawn from the 2005 Beijing Household Travel Survey, a Nested Logit model was applied to construct the interdependent model between commuters' trip chain and travel model choices. The model structures in the direction from travel mode to trip chain and in the opposite direction were set up. The decisionmaking from trip chain to travel mode is relatively reasonable, reflecting that commuters are adept to think about the daily activity at first and then to choose an appropriate travel mode under the constraints of trip chain. The researchers concluded that if public transit systems want to attract more passengers, they not only need to improve the service level of public transportation, such as comfort and security, but also need to put forward the corresponding traffic demand management measures according to the characteristics of the complex travel chain and meet the needs of residents using complex trip chain mode. Reference [8] studied the problem of the shift of car commuters to public transport; the effect of main parameter of the model has been analyzed. The researchers believed that decreasing the opportunity profit of nonshifters is needed in order to promote the shift. When the effect of the policy stimulation cannot counteract the opportunity profit of nonshifters, the policy should incline to the high density group. The conclusion of these papers is similar to ours, showing that city traffic commute mode choice decided on the overall city traffic development strategy; commuters will choose traffic mode according to the benefits of the public transport and cars.

In our example, the threshold value of system is the boundary status in public transit advantage growth and private cars travel restrictions; the payoffs matrix is only an assumption of ideal situation; we can carry on further quantitative analysis or define a suitable regression function for the understanding of factors in further study; at the same time, the initial state of system is also needed for sufficient investigation and analysis. So we can use the evolutionary game model to analyze the real problem about urban transportation development policy.

\section{Conflict of Interests}

The authors declare that there is no conflict of interests regarding the publication of this paper.

\section{Acknowledgment}

This work was supported by the National Natural Science Foundation of China (no. 61174188).

\section{References}

[1] G. G. He, Y. M. Ji, and H. T. Liu, "Choice for travel modes based on the two-level game," Journal of Chang'an University (Social Science Edition), vol. 8, pp. 4-7, 2006.

[2] H. Y. Xiao and X. J. Wang, "A study of trip model choice behavior of traveler based on the evolutionary game under the participation of government," Journal of Industrial Engineering and Engineering Management, vol. 24, pp. 115-118, 2010.

[3] X. G. Chen, J. Zhou, and Z. T. Zhu, "Evolutionary game analysis of the travel mode choice for urban travelers," Journal of Industrial Engineering/Engineering Management, vol. 23, pp. 140-142, 2009.

[4] Z. Liu, W. Deng, and Y. Ji, "Influence of land use characteristics and trip attributes on commuting mode choice: a case of Nanjing," Journal of Southeast University, vol. 30, no. 1, pp. 107112, 2014.

[5] E. J. Gonzales and C. F. Daganzo, "Morning commute with competing modes and distributed demand: user equilibrium, system optimum, and pricing," Transportation Research Part B: Methodological, vol. 46, no. 10, pp. 1519-1534, 2012.

[6] H. Wu, M. Y. Yang, and L. Y. Chen, "An analyzes on complexity and evolutionary stability in co-petition games," System Engineering-Theory and Practice, vol. 2, pp. 90-94, 2004.

[7] L. Kun, J. Zhicai, and Z. Fang, "Research on commuter's choice behavior between travel mode and trip chain," Journal of Highway and Transportation Research and Development, vol. 27, no. 6, pp. 107-111, 2010.

[8] L. Yang and D. Qian, "Evolutionary game analysis on modal shift of car commuters to public transport," Journal of Beijing Jiaotong University, vol. 38, no. 2, pp. 151-156, 2014. 

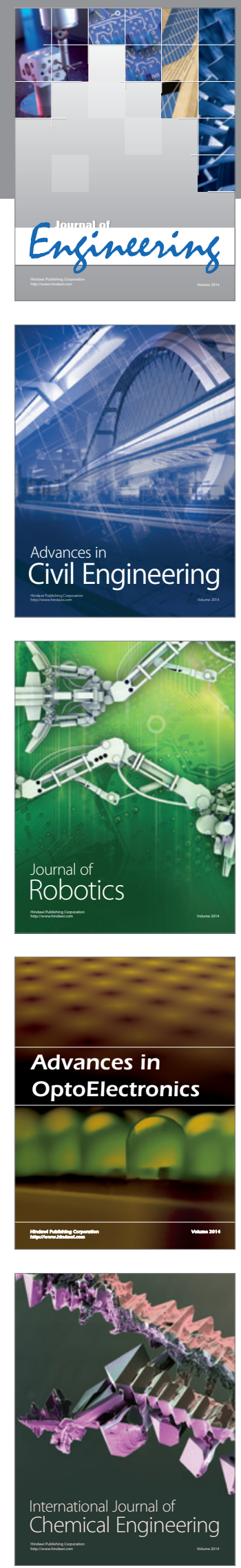

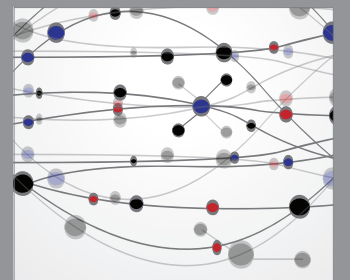

The Scientific World Journal
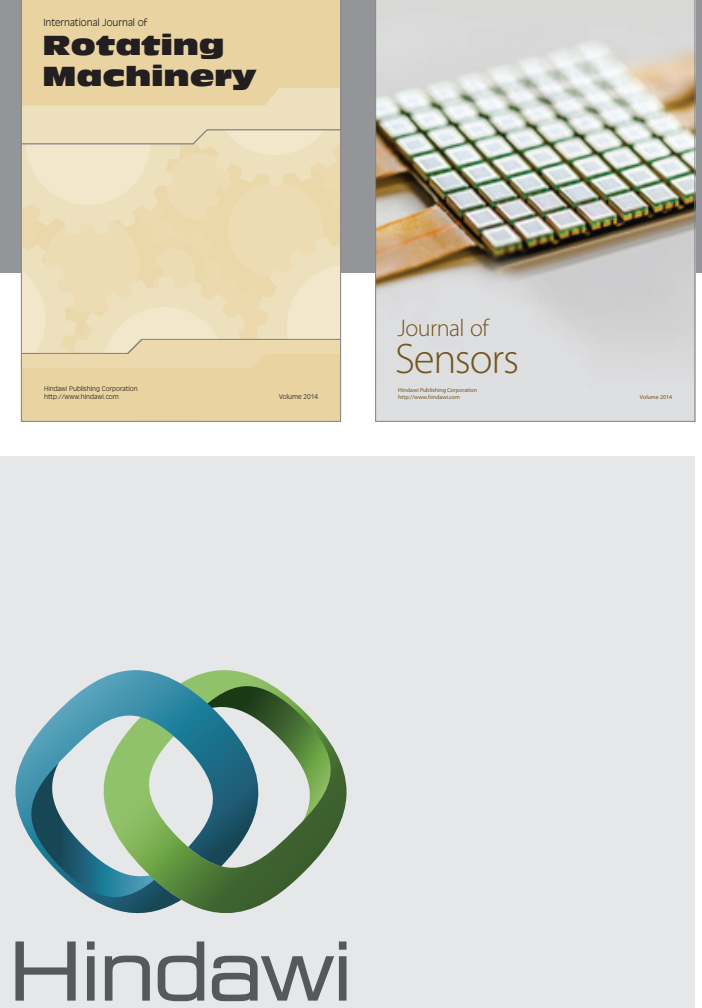

Submit your manuscripts at http://www.hindawi.com
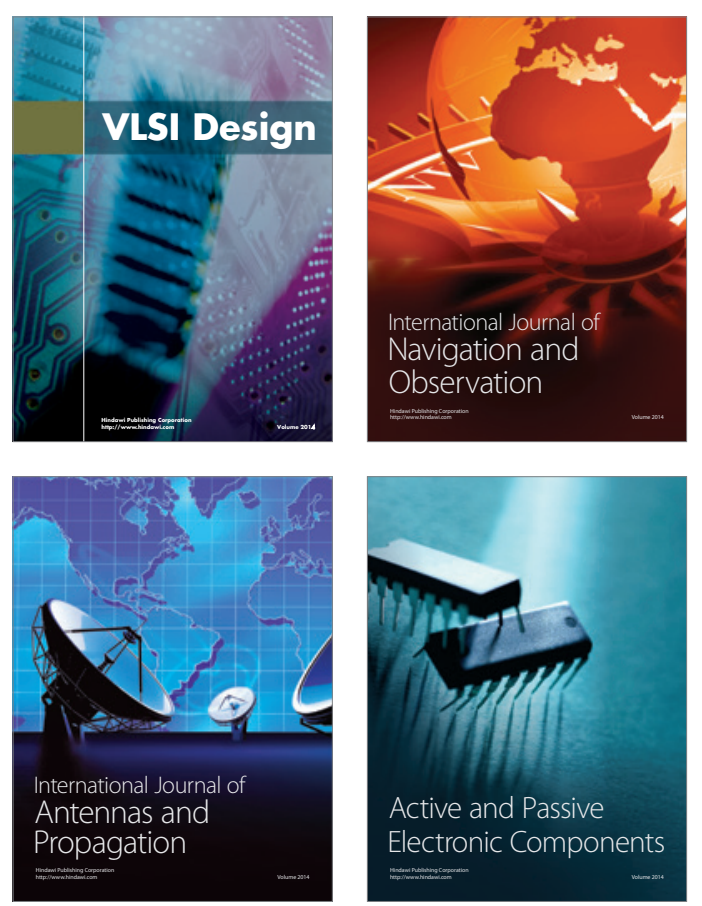
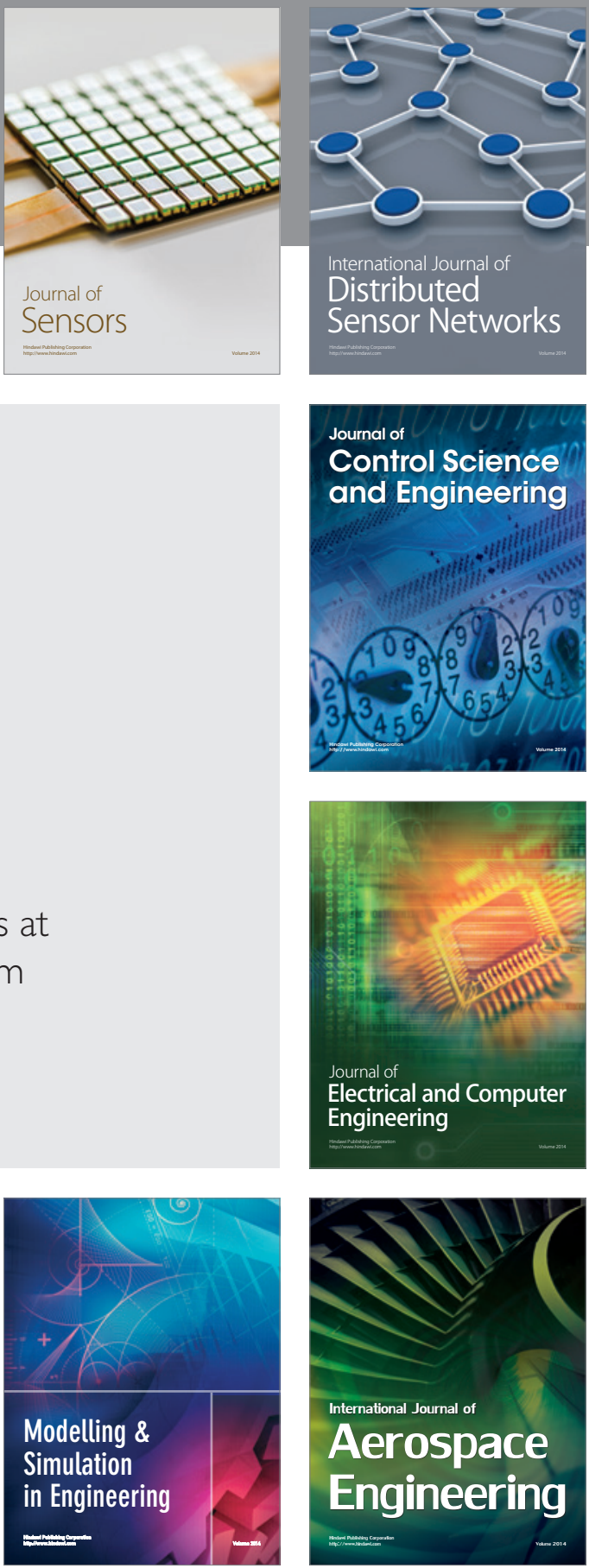

Journal of

Control Science

and Engineering
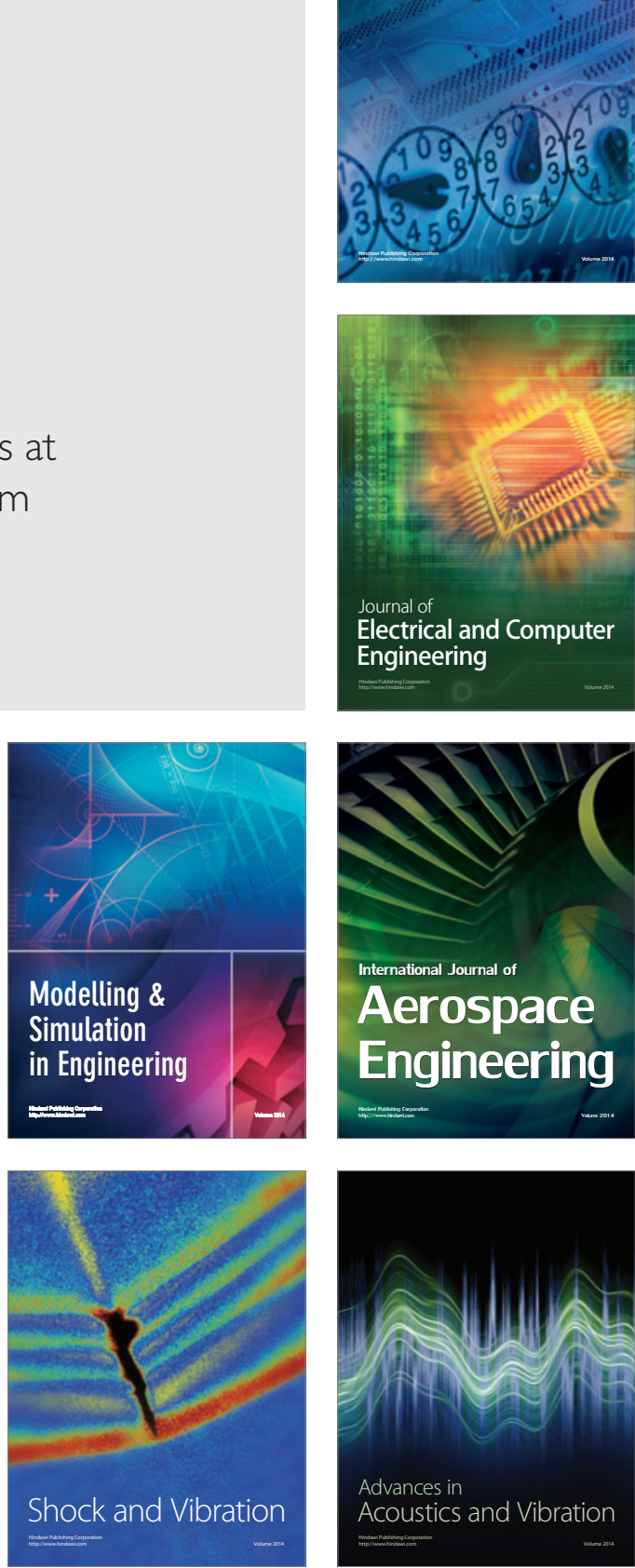